Published in final edited form as:

Am J Bioeth. 2015 ; 15(7): 17-19. doi:10.1080/15265161.2015.1039733.

\title{
Scrutinizing the Right Not to Know
}

\author{
Benjamin E. Berkman, \\ National Institutes of Health \\ Sara Chandros Hull, and \\ National Institutes of Health \\ Leslie G. Biesecker \\ National Institutes of Health
}

\begin{abstract}
There is an important ongoing debate about how best to incorporate individual choice into the management of clinically significant findings generated by large-scale genomic sequencing. While patient choice is obviously a core principle of clinical ethics, the rapidly evolving field of genomic medicine has forced researchers, clinicians, and bioethicists to reexamine traditional conceptions about the right not to know ("RNTK"). Specifically, there has been a robust debate about whether there are any (perhaps limited) circumstances where it is ethically appropriate to not give patients an opportunity to choose whether or not to learn genetic information about themselves (Green et al. 2013). The authors of the target article clearly support an autonomy-focused solution to this problem (Làzaro-Muñoz et al. 2015). In this response, we explore some of their legal, normative, and empirical claims that we believe require closer scrutiny.
\end{abstract}

\section{THE LEGAL RIGHT TO REFUSE MEDICAL INFORMATION}

The authors make a legal claim that the constitutional right to refuse medical treatment implies a constitutional right to refuse medical information. We believe that this mistakenly conflates the concepts of bodily and psychological integrity, leading to a premature legal conclusion. There is no direct case law establishing a constitutionally protected right not to learn medically significant information about oneself, and any legal argument would have to build on the Fourteenth Amendment individual liberty cases establishing the right to refuse medical treatment. Cruzan v. Director (1990) and other such cases are generally about physical interventions like hydration and nutrition, and significantly rely on informed

\footnotetext{
Address correspondence Benjamin E. Berkman, National Institutes of Health, Department of Bioethics, Building 10/Room 1C118, 10 Center Drive, MSC 1156, Bethesda, MD, USA. berkmanbe@mail.nih.gov.

Publisher's Disclaimer: Taylor \& Francis makes every effort to ensure the accuracy of all the information (the "Content") contained in the publications on our platform. However, Taylor \& Francis, our agents, and our licensors make no representations or warranties whatsoever as to the accuracy, completeness, or suitability for any purpose of the Content. Any opinions and views expressed in this publication are the opinions and views of the authors, and are not the views of or endorsed by Taylor \& Francis. The accuracy of the Content should not be relied upon and should be independently verified with primary sources of information. Taylor and Francis shall not be liable for any losses, actions, claims, proceedings, demands, costs, expenses, damages, and other liabilities whatsoever or howsoever caused arising directly or indirectly in connection with, in relation to or arising out of the use of the Content.

Publisher's Disclaimer: This article may be used for research, teaching, and private study purposes. Any substantial or systematic reproduction, redistribution, reselling, loan, sub-licensing, systematic supply, or distribution in any form to anyone is expressly forbidden. Terms \& Conditions of access and use can be found at http://www.tandfonline.com/page/terms-and-conditions
} 
consent jurisprudence, which was based on common law ideas of battery (unwanted, offensive touching). The legal reasoning in these cases explicitly discussed the importance of protecting bodily integrity, with no mention of psychological integrity. Without getting into a detailed legal analysis, we believe that courts would find purchase in this distinction, and they would likely need to engage in an independent assessment to determine whether psychological integrity independently merits constitutional protection. While a range of outcomes is certainly possible, courts are generally reluctant to expand the liberty interests protected by the Fourteenth Amendment due process clause, and it seems reasonable to imagine that in a case of first impression, courts would be loath to create a constitutionally protected liberty interest in something as amorphous and potentially expansive as psychological integrity.

\section{HOW BROADLY ACCEPTED IS THE RIGHT NOT TO KNOW?}

Second, in a number of places the authors make claims about the broad acceptance of a strong RNTK. While there is support for this position, we believe that the authors do not sufficiently recognize the fact that the RNTK is very much contested in the philosophical literature, and that even staunch proponents recognize that the RNTK can be overridden. There is a substantial philosophical literature about the "right not to know" in the late 1990s and early 2000s, with a significant split between those arguing in favor of such a right, and those opposed. There are two primary lines of reasoning challenging the RNTK. The first objection posits that the very concept of an autonomy-based RNTK is incoherent (Rhodes 1998; Harris and Key-wood 2001). Knowledge is necessary in order to exercise autonomy. One needs to know that there is a question in order to make a decision, so not knowing undermines one's ability to make an autonomous choice. The second objection is based on a concern about harm to others (Austad 1996). Genetic information unavoidably involves relatives, and one has an obligation to learn readily available information about your health in order to prevent harm to third parties. For example, knowledge about your risk for a disease implies that relatives could have a similar risk, which should be disclosed.

Setting these two specific objections aside, it should also be noted that even among more ardent supporters in the philosophical literature, the RNTK is qualified as something that only applies in certain contexts and that can be overridden. For example, Graham Laurie (1999), one of the more vocal proponents for the RNTK, argues that it isn't an absolute right but must be weighed against other compelling interests. His claim is that the RNTK should be given "prima facie respect which should be accorded unless due cause for disclosure can be shown," suggesting things like severity of the condition, likelihood of onset, and availability of a potential cure as conditions that might justify disclosure. Unless one views the right not to know as absolute, it seems plausible that much of the early philosophical literature on this topic would be consistent with a panel approach if only this kind of high value medical information is included. 


\section{COMPREHENSIVELY WEIGHING HARMS AND BENEFITS OF THE MENU AND PANEL APPROACHES}

In advocating for a menu approach, the authors spend some time focusing on personal autonomy considerations, such as "the numerous personal and familial, emotional, economic and medical interests that come into play when an individual is deciding whether to know or not know a potential genomic risk." Our third concern is that a focus on the autonomy perspective does not allow for a comprehensive analysis of the harms and benefits associated with various possible return of results policies. Any return of results policy will necessarily make a mistake in one of two directions: unwanted disclosure, or lost opportunity for medical intervention. Framing the debate purely in terms of autonomy misses an opportunity to weigh the harms that might ensue if return of results policies allow for easy opt-out (e.g., menu approach) and the potential benefits of policies that codify a default to disclose all medically significant findings (e.g., panel approach).

While a menu approach may seem appealing as supporting the notion of autonomy, a comprehensive analysis would assess the frequency with which such a policy could lead to missed opportunities to help someone with a potentially serious genetic risk. The authors acknowledge that "the complexity of genomic information and the consequences of opting out are an undeniable challenge for the menu approach." The question, then, is, how many people undergoing genomic sequencing would erroneously or accidentally not receive potentially lifesaving information if we actively solicit patient preferences about knowing or not knowing?

On the other side of the ledger, a panel approach will certainly burden some people with information that they otherwise would not have wanted. But in order to fully assess the harms of such a policy, we would first need to know how many people would decline to learn medically significant information. Setting aside terminally ill patients and others who would have a clear reason for declining treatment, one can empirically test the reasonable hypothesis that most people would want to know this kind of information. We would also want to know about the frequency and magnitude of harms associated with unwanted disclosure. There are data from the affective forecasting literature showing that negative psychological effects of receiving a positive diagnosis for many untreatable conditions (e.g., Alzheimer's disease [AD], Huntington's) are generally transient and mild. More evidence would certainly be useful, but this literature at least raises important questions about whether we "systematically overestimate the durability and intensity of the affective impact of events on well-being," thereby creating a "culture of risk-aversion in which patients may be opting out of potentially beneficial diagnostic and treatment regimes" (Peters et al. 2013).

\section{GENETIC EXCEPTIONALISM}

Finally, the authors don't support their exceptional views about genomic testing, failing to explain why the menu approach is appropriate for genomic testing but not for nongenomic findings where disclosure of incidental findings (without informed consent) is standard practice. If a physician orders a blood panel or radiologic study for a particular reason and it reveals a medically important finding unrelated to the test's original indication, there is no 
concern about the ethical appropriateness of disclosing that information to the patient, nor is there an expectation that prior consent is required prior to disclosure. A certain amount of genetic exceptionalism is understandable, given that genomic medicine is rapidly evolving, the range of benefits and harms of genomic information is not yet well characterized, and the standard of care is very much in flux. But if commentators intend to argue that genetic information should be treated differently than other kinds of medical information, they must explain why that must be the case. Otherwise, their menu approach to incidental information would need to be extended to all realms of medicine, including the physical examination, surgery, imaging, and all biochemical analyte measurements.

\section{CONCLUSION}

As medical practice evolves to incorporate genomic sequencing technology, the debate about the appropriate contours of the RTNK will likely continue to simmer. While the target article helpfully unpacks some of the common arguments in favor of a strong RNTK, we believe that more legal, normative, and empirical work needs to be done to clearly defend the necessity of a menu approach for genomics and to articulate why such an approach doesn't apply to medicine more broadly. We suspect that further research and analysis will highlight weaknesses in the menu approach for genomic sequencing and will ultimately weaken arguments for a strong RNTK genomic findings.

\section{REFERENCES}

Austad T 1996 The right not to know-Worthy of preservation any longer? An ethical perspective. Clinical Genetics 50: 85-88. [PubMed: 8937766]

Director Cruzan v.. Missouri Department of Health. 1990497 U.S. 261.

Green RC, Berg JS, Grody WW, et al. 2013 ACMG recommendations for reporting of incidental findings in clinical exome and genome sequencing. Genetics in Medicine 15(7): 565-574. 10.1038/ gim.2013.73 [PubMed: 23788249]

Harris J, and Keywood K 2001 Ignorance, information and autonomy. Theoretical Medicine 22: 415436. 10.1023/A:1013058801622

Laurie G 1999 In defense of ignorance: Genetic information and the right not to know. European Journal of Health Law 6: 119-132. 10.1163/15718099920522730 [PubMed: 11657815]

Làzaro-Muñoz G, Conley JM, Davis AM, Van Riper M, Walker RL, and Juengst ET. 2015 Looking for trouble: Preventive genomic sequencing in the general population and the role of patient choice. American Journal of Bioethics 15(7): 3-14.

Peters SA, Laham SM, Pachter N, et al. 2013 The future in clinical genetics; Affective forecasting biases in patient and clinician decision making. Clinical Genetics 85: 312-317. http://dx.doi. org/ 10.1111/cge.12255 [PubMed: 23952534]

Rhodes R 1998 Genetic links, family ties, and social bonds: Rights and responsibilities in the face of genetic knowledge. Journal of Medicine and Philosophy 23(1): 10-30. 10.1076/jmep.23.1.10.2594 [PubMed: 9555632] 